\title{
Specially Processed Heterogenous Bone and Cartilage Transplants in Nasal Surgery
}

\author{
By Graeme M. Clark (Melbourne)
}

IN nasal surgery, cartilage or bone transplants are required for support or correction of cosmetic deformities. When autogenous material is readily available, it should be used in preference to homogenous or heterogenous material. Sometimes this means, however, an iliac bone or rib cartilage graft. These procedures have a certain morbidity and the grafts are not always readily accepted by the patient. For this reason, there is a place for heterografts, especially when their antigenicity is reduced. Embryo calf bone and cartilage can be specially treated by lyophilization and surface active agents to reduce its antigenicity (Dingwall and Millonig, I964) and this material has been used in the present clinical study.

Cartilage and bone transplants are often required to maintain support and resist deforming forces. It has been shown (Clark, I968) that a septal strut of heterogenous bone can be effective in supporting the nasal dorsum in a patient with a saddle nose due to injury. Consequently, this study has been undertaken to see how well the specially-processed heterogenous bone and cartilage would resist deforming forces and become incorporated into the host tissues.

It was considered necessary to use the material in a number of different sites as this would enable one to assess better the effects of different degrees of muscle pull and tissue tension on the rate of its absorption. Assessment of absorption and rejection in the septum can be made difficult by limited access. This was another reason why subcutaneous and other sites were selected, so that absorption could be better assessed by inspection and palpation.

This clinical study has been undertaken in seven patients with a variety of problems due to loss of support of one or more nasal structures. As there had been no previous evidence that the material was superior to autogenous transplants, the specially-processed bone and cartilage were only used in patients where sufficient autogenous material could not be obtained, and after discussion with the patient.

\section{Patient I}

\section{Case Reports}

This patient was a 48-year-old male who presented with a 30-year history of nasal obstruction and deformity following three nasal fractures. As shown in 


\section{Graeme M. Clark}

Fig. I the nose was broad and deviated to the left. Previous trauma had resulted in loss of septal support and a supratip depression of the nasal dorsum. The septum was markedly deviated to the right.

At operation, a great deal of scar tissue was found in the septum and around the nasal bones. For this reason, it was felt that a ventral supporting strut would not provide adequate support. A specially-processed piece of heterogenous cartilage was implanted in the supratip region, as insufficient autogenous material could be obtained from the septum. A piece of cartilage $\mathrm{I} \cdot 5 \mathrm{~cm} . \times 0 \cdot 75$ $\mathrm{cm}$. was placed in a pocket overlying the upper lateral cartilages. A routine rhinoplasty was also performed.

The post-operative result a year later can be seen in Fig. $x$. There was no absorption of the cartilage implant, and no infection or immune reaction occurred at any stage.

\section{Patient 2}

This patient was a 2I-year-old girl complaining of difficulty in breathing through the right nostril. On examination, the disability was found to be due to an alar collapse (Fig. 2); the nasal septum was midline.
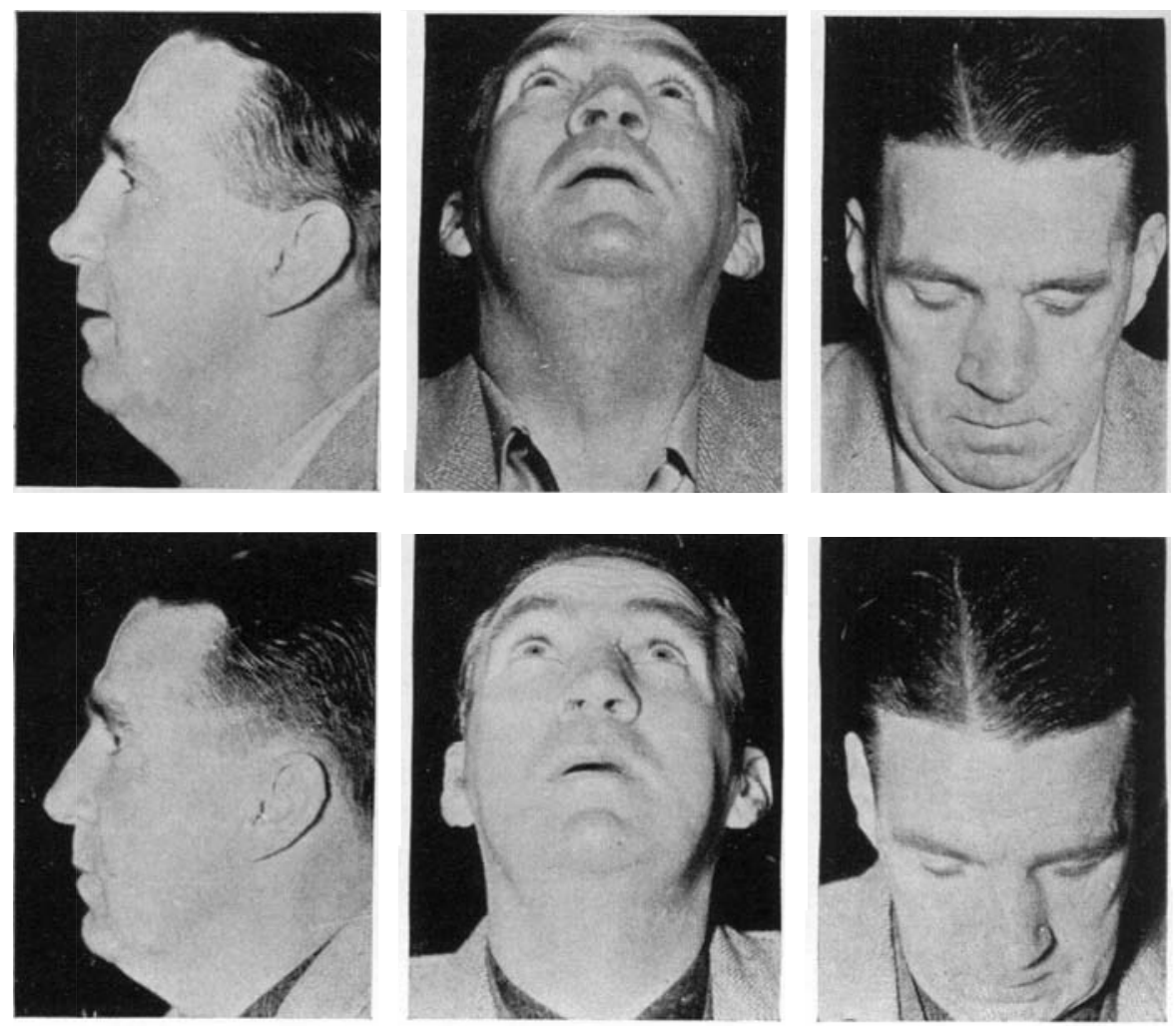

FIG. I.

Patient No. I.

Top: Patient before operation. Bottom: Patient after operation.

276 


\section{Bone and Cartilage Transplants in Nasal Surgery}

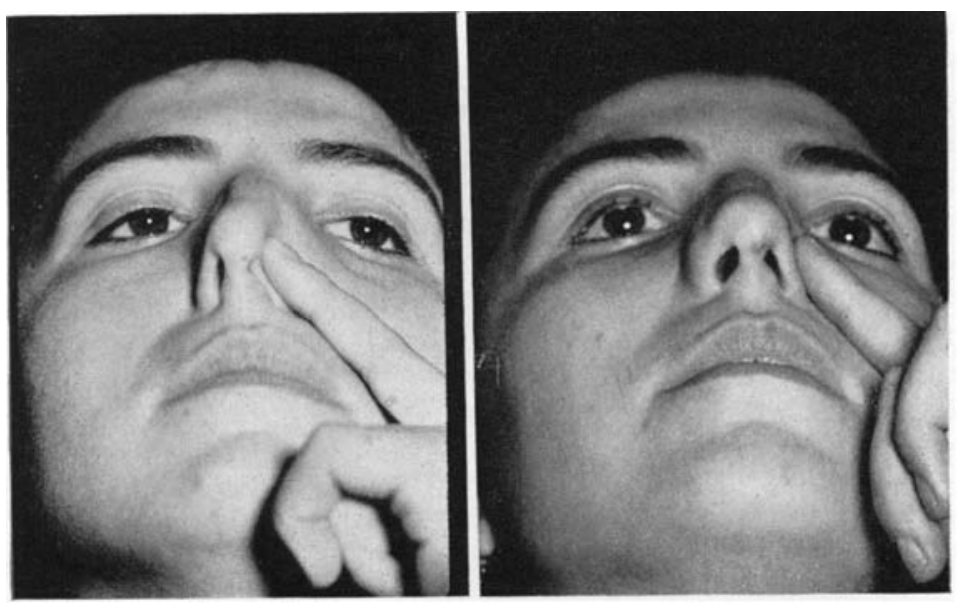

FIG. 2.

Patient No. 2.

Left: I're-operative photograph of patient during deep inspiration.

Right: Post-operative photograph of patient during deep inspiration.

At operation a pocket was fashioned in the tissue underlying the right upper and lower lateral cartilages. These were found to be atrophic, and so a small piece of specially-prepared heterogenous cartilage was implanted to provide mechanical support. Heterogenous cartilage was used, as a piece could be selected with a slight convexity. The spring in this piece of cartilage then assisted in keeping the nasal valve open during inspiration.

Following the operation, there was a little bruising and swelling of the nasal tissues, and in case infection had occurred, immediate antibiotic therapy was begun. This was the only case where infection may have occurred, and it was never proved.

The cartilage implant maintained adequate support, and a satisfactory airway was still present a year later (Fig. 2). During this period, some resorption occurred, and this may have been due to the constant movement as a result of the dilator naris muscle.

\section{Patient 3}

This patient was a 40-year-old male with nasal obstruction and a cosmetic deformity. He had a broad nose, osseous hump, supratip saddle, recession of the columella and deviated nasal septum.

A combined septoplasty and rhinoplasty was performed, and to improve the airway, it was necessary to remove an inferior strip from the septum and the maxillary crest, and to excise part of the anterior nasal spine. To provide support to the supratip region and improve the columellar recession, a heterogenous cortical bone transplant was implanted in the distal part of the septum.

There was no evidence of infection or resorption during the post-operative course nor when the patient was reviewed after 12 months. 


\section{Graeme M. Clark}

\section{Patient 4}

This patient was a 30-year-old male complaining of nasal obstruction. He had been a boxer and had suffered multiple injuries of the nose. He had a broad nose, supratip saddle, retraction of the columella, and a marked deviation of the septum to the right.

A combined septoplasty and rhinoplasty was performed. The septal cartilage was extensively replaced with fibrous tissue and wide excision was necessary. A heterogenous cortical bone transplant was inserted into the distal part of the septum to maintain support to the supratip region and retracted columella.

There was no evidence of any reaction to the implant during the postoperative period. Absorption of the transplant did not occur during the period of observation. However, the patient could not be traced after 6 months.

\section{Patient 5}

This patient was a 20 -year-old male who had symptoms from a non-specific septal perforation.

At operation the septal cartilage surrounding the perforation was found to be atrophic. The mucous membrane was elevated from the surrounding septum, and posterior and superior relaxing incisions made. A piece of specially-processed heterogenous cartilage was introduced, and the mucous membrane sutured together over the implant.

The heterogenous cartilage was well tolerated, no absorption occurred, but the patient was not reviewed after 6 months.

\section{Patient 6}

This patient was a 46 -year-old male who also had symptoms due to a septal perforation.

A similar operation to that on patient 5 was performed. A piece of speciallyprocessed heterogenous cartilage was inserted into the septum, and a mucosal flap sutured over one side.

Post-operatively, a small central area broke down but otherwise the implant was well tolerated.

\section{Patient 7}

This patient was a 20-year-old male who had a nasal deformity due to trauma. A previous septoplasty and rhinoplasty had been performed. On clinical examination the nose was still broad and a supratip saddle was present.

The nose was narrowed in the usual way and a piece of specially-prepared heterogenous cartilage implanted in the supratip region.

There was no evidence of rejection or absorption. The patient was followed up for 6 months.

\section{Discussion}

The results of this study on seven patients show that speciallyprocessed heterogenous bone and cartilage are well tolerated by the body, as no immune reactions occurred. In one case infection was suspected but not proved.

$$
278
$$




\section{Bone and Cartilage Transplants in Nasal Surgery}

All patients were reviewed for at least 6 months, although two could not be traced after this time. In two patients some absorption of cartilage occurred. In one case the cartilage was implanted adjacent to the lower lateral cartilage, and movement probably facilitated absorption. In the other patient, the cartilage had been implanted into the nasal septum to correct a septal perforation. This absorption may have been related to the poor blood supply in the area, and to the technical difficulties of providing an adequate mucosal covering.

Although this is not a large series there are sufficient numbers to indicate that infection is uncommon. There appears to be a trend towards progressive absorption of heterogenous cartilage, but cortical bone transplants appear to resist absorption for at least 6 months to a year.

These results compare favourably with the two other reported series on the use of processed heterogenous implants in rhinoplasties and septal surgery.

In 1962, Cottle reported a series of 520 patients operated on over 3 years. Of these, there were 478 in whom acceptable results could be recorded. There were thirty-two ( 7 per cent.) complications of significance which were related to the use of the bone and cartilage. Processed cancellous bovine bone was used in a separate series of 85 patients. The results showed that it was superior to any heterogenous organic substance previously used, and there were fewer complications than in a control group of sixtynine patients in whom autogenous bone and cartilage were used.

In I965, Ellis reported on the use of Boplant (Squibb) cartilage and bone in thirteen patients. Heterogenous cartilage was used in three patients, a slight immediate reaction occurred in one, a good result in another, and the material was completely absorbed in a third. Heterogenous bone was used in ten patients in the cancellous form. There was an early reaction in one case, but otherwise the results were good. No absorption occurred except for the development of a small sinus in one case where the material had been transplanted into the septum.

An orthopaedic clinical trial of Boplant was carried out by Anderson et al. (1963). They used heterogenous bone transplants in 150 patients with infection in four cases. There was no clinical evidence of foreign-body reaction or immunological response. In nine cases a biopsy showed that the material had been incorporated into the host tissue.

These results indicate that the specially-processed bone and cartilage are as well tolerated by the body as autogenous material. They have a lower rejection rate than heterogenous material that is not speciallyprocessed (ox bone and cartilage).

Not only have the experimental and orthopaedic trials shown that specially-processed heterogenous bone is well incorporated into the body tissues, but they have shown that it will resist mechanical stresses. For this reason, it seems suitable material to use when nasal support is required and autogenous bone is not readily available. 


\section{Graeme M. Clark}

\section{Summary}

Specially-processed heterogenous bone and cartilage have been used in a clinical trial on seven patients. The results, taken in conjunction with the reported series, indicate that the heterogenous bone is only absorbed slowly, if at all. Experimental studies show that it is readily incorporated into the body tissues, and the present series indicates that it has the capacity to resist mechanical stresses. Consequently, its use is advocated for certain types of nasal deformity where autogenous bone is not readily available.

\section{Acknowledgments}

Squibb and Sons provided the specially-processed heterogenous bone and cartilage.

\section{REFERENCES}

Anderson, K. J., Lecoce, J. K., and Mooney, J. G. (1963) Clin. Orthop., 29, 248. Clark, G. M. (In press) Arch. oto-laryng.

Cottle, M. H. (I962) The Eighth Annual Meeting of the American Rhinologic Society.

Dingwall, J. A., and Millonig, R. C. (I964) Int. Rhinol., 2, 25.

Ellis, F. (1965) Med. J. Aust., 1, 583 .

I3 Gorling Street,

Lane Cove, 2066,

N.S.W., Australia. 


\section{University Library}

\section{- M M I N E R VA A gateway to Melbourne's research publications}

Minerva Access is the Institutional Repository of The University of Melbourne

Author/s:

Clark, Graeme M.

Title:

Specially processed heterogenous bone and cartilage transplants in nasal surgery

Date:

1969

Citation:

Clark, G. M. (1969). Specially processed heterogenous bone and cartilage transplants in nasal surgery. Journal of Laryngology and Otology, 83(3), 275-280.

Persistent Link:

http://hdl.handle.net/11343/27112 